\title{
Contents of Volumes in the Metal Ions in Life Sciences Series
}

edited by the SIGELs

\section{Volumes 1-4}

published by John Wiley \& Sons, Ltd., Chichester, UK (2006-2008)

$<$ http://www.Wiley.com/go/mils>

$<$ http://www.wiley.com/WileyCDA/Section/id-300350.html>

\section{Volumes 5-9}

published by the Royal Society of Chemistry, Cambridge, UK (2009-2011) since 2015 by Walter de Gruyter GmbH, Berlin, Germany

$<$ http://www.bioinorganic-chemistry.org/mils $><$ http://www.mils-WdG.com $>$

\section{Volumes 10-16}

published by Springer Science \& Business Media BV, Dordrecht, The Netherlands (2012-2014; MILS-10 to MILS-14)

and by Springer International Publishing AG, Cham, Switzerland (2015-2016; MILS-15 and MILS-16)

$<$ http://www.bioinorganic-chemistry.org/mils>

and from Volume 17 on

published by Walter de Gruyter GmbH, Berlin, Germany

$<$ http://www.mils-WdG.com>

\section{Volume 1: Neurodegenerative Diseases and Metal Ions}

1. The Role of Metal Ions in Neurology. An Introduction Dorothea Strozyk and Ashley I. Bush

2. Protein Folding, Misfolding, and Disease Jennifer C. Lee, Judy E. Kim, Ekaterina V. Pletneva, Jasmin Faraone-Mennella, Harry B. Gray, and Jay R. Winkler

3. Metal Ion Binding Properties of Proteins Related to Neurodegeneration Henryk Kozlowski, Marek Luczkowski, Daniela Valensin, and Gianni Valensin 
4. Metallic Prions: Mining the Core of Transmissible Spongiform Encephalopathies

David R. Brown

5. The Role of Metal Ions in the Amyloid Precursor Protein and in Alzheimer's Disease

Thomas A. Bayer and Gerd Multhaup

6. The Role of Iron in the Pathogenesis of Parkinson's Disease Manfred Gerlach, Kay L. Double, Mario E. Götz, Moussa B. H. Youdim, and Peter Riederer

7. In Vivo Assessment of Iron in Huntington's Disease and Other Age-Related Neurodegenerative Brain Diseases George Bartzokis, Po H. Lu, Todd A. Tishler, and Susan Perlman

8. Copper-Zinc Superoxide Dismutase and Familial Amyotrophic Lateral Sclerosis

Lisa J. Whitson and P. John Hart

9. The Malfunctioning of Copper Transport in Wilson and Menkes Diseases Bibudhendra Sarkar

10. Iron and Its Role in Neurodegenerative Diseases Roberta J. Ward and Robert R. Crichton

11. The Chemical Interplay between Catecholamines and Metal Ions in Neurological Diseases

Wolfgang Linert, Guy N. L. Jameson, Reginald F. Jameson, and Kurt A. Jellinger

12. Zinc Metalloneurochemistry: Physiology, Pathology, and Probes Christopher J. Chang and Stephen J. Lippard

13. The Role of Aluminum in Neurotoxic and Neurodegenerative Processes Tamás Kiss, Krisztina Gajda-Schrantz, and Paolo F. Zatta

14. Neurotoxicity of Cadmium, Lead, and Mercury Hana R. Pohl, Henry G. Abadin, and John F. Risher

15. Neurodegerative Diseases and Metal Ions. A Concluding Overview Dorothea Strozyk and Ashley I. Bush

Subject Index

\section{Volume 2: Nickel and Its Surprising Impact in Nature}

1. Biogeochemistry of Nickel and Its Release into the Environment Tiina M. Nieminen, Liisa Ukonmaanaho, Nicole Rausch, and William Shotyk

2. Nickel in the Environment and Its Role in the Metabolism of Plants and Cyanobacteria Hendrik Küpper and Peter M. H. Kroneck 
3. Nickel Ion Complexes of Amino Acids and Peptides

Teresa Kowalik-Jankowska, Henryk Kozlowski, Etelka Farkas, and Imre Sóvágó

4. Complex Formation of Nickel(II) and Related Metal Ions with Sugar Residues, Nucleobases, Phosphates, Nucleotides, and Nucleic Acids Roland K. O. Sigel and Helmut Sigel

5. Synthetic Models for the Active Sites of Nickel-Containing Enzymes Jarl Ivar van der Vlugt and Franc Meyer

6. Urease: Recent Insights in the Role of Nickel Stefano Ciurli

7. Nickel Iron Hydrogenases Wolfgang Lubitz, Maurice van Gastel, and Wolfgang Gärtner

8. Methyl-Coenzyme M Reductase and Its Nickel Corphin Coenzyme $\mathrm{F}_{430}$ in Methanogenic Archaea Bernhard Jaun and Rudolf K. Thauer

9. Acetyl-Coenzyme A Synthases and Nickel-Containing Carbon Monoxide Dehydrogenases

Paul A. Lindahl and David E. Graham

10. Nickel Superoxide Dismutase

Peter A. Bryngelson and Michael J. Maroney

11. Biochemistry of the Nickel-Dependent Glyoxylase I Enzymes Nicole Sukdeo, Elisabeth Daub, and John F. Honek

12. Nickel in Acireductone Dioxygenase

Thomas C. Pochapsky, Tingting Ju, Marina Dang, Rachel Beaulieu, Gina Pagani, and Bo OuYang

13. The Nickel-Regulated Peptidyl-Prolyl cis/trans Isomerase SlyD Frank Erdmann and Gunter Fischer

14. Chaperones of Nickel Metabolism Soledad Quiroz, Jong K. Kim, Scott B. Mulrooney, and Robert P. Hausinger

15. The Role of Nickel in Environmental Adaptation of the Gastric Pathogen Helicobacter pylori

Florian D. Ernst, Arnoud H. M. van Vliet, Manfred Kist, Johannes G. Kusters, and Stefan Bereswill

16. Nickel-Dependent Gene Expression Konstantin Salnikow and Kazimierz S. Kasprzak

17. Nickel Toxicity and Carcinogenesis

Kazimierz S. Kasprzak and Konstantin Salnikow

Subject Index

\section{Volume 3: The Ubiquitous Roles of Cytochrome P450 Proteins}

1. Diversities and Similarities of P450 Systems: An Introduction Mary A. Schuler and Stephen G. Sligar 
2. Structural and Functional Mimics of Cytochromes P450

Wolf-D. Woggon

3. Structures of P450 Proteins and Their Molecular Phylogeny

Thomas L. Poulos and Yergalem T. Meharenna

4. Aquatic P450 Species

Mark J. Snyder

5. The Electrochemistry of Cytochrome P450

Alan M. Bond, Barry D. Fleming, and Lisandra L. Martin

6. P450 Electron Transfer Reactions

Andrew K. Udit, Stephen M. Contakes, and Harry B. Gray

7. Leakage in Cytochrome P450 Reactions in Relation to Protein Structural Properties

Christiane Jung

8. Cytochromes P450. Structural Basis for Binding and Catalysis Konstanze von König and Ilme Schlichting

9. Beyond Heme-Thiolate Interactions: Roles of the Secondary Coordination Sphere in P450 Systems

Yi Lu and Thomas D. Pfister

10. Interactions of Cytochrome P450 with Nitric Oxide and Related Ligands Andrew W. Munro, Kirsty J. McLean, and Hazel M. Girvan

11. Cytochrome P450-Catalyzed Hydroxylations and Epoxidations Roshan Perera, Shengxi Jin, Masanori Sono, and John H. Dawson

12. Cytochrome P450 and Steroid Hormone Biosynthesis Rita Bernhardt and Michael R. Waterman

13. Carbon-Carbon Bond Cleavage by P450 Systems James J. De Voss and Max J. Cryle

14. Design and Engineering of Cytochrome P450 Systems Stephen G. Bell, Nicola Hoskins, Christopher J. C. Whitehouse, and Luet L. Wong

15. Chemical Defense and Exploitation. Biotransformation of Xenobiotics by Cytochrome P450 Enzymes

Elizabeth M. J. Gillam and Dominic J. B. Hunter

16. Drug Metabolism as Catalyzed by Human Cytochrome P450 Systems F. Peter Guengerich

17. Cytochrome P450 Enzymes: Observations from the Clinic Peggy L. Carver

Subject Index

\section{Volume 4: Biomineralization. From Nature to Application}

1. Crystals and Life: An Introduction Arthur Veis 
2. What Genes and Genomes Tell Us about Calcium Carbonate Biomineralization Fred H. Wilt and Christopher E. Killian

3. The Role of Enzymes in Biomineralization Processes Ingrid M. Weiss and Frédéric Marin

4. Metal-Bacteria Interactions at Both the Planktonic Cell and Biofilm Levels Ryan C. Hunter and Terry J. Beveridge

5. Biomineralization of Calcium Carbonate. The Interplay with Biosubstrates Amir Berman

6. Sulfate-Containing Biominerals Fabienne Bosselmann and Matthias Epple

7. Oxalate Biominerals Enrique J. Baran and Paula V. Monje

8. Molecular Processes of Biosilicification in Diatoms Aubrey K. Davis and Mark Hildebrand

9. Heavy Metals in the Jaws of Invertebrates Helga C. Lichtenegger, Henrik Birkedal, and J. Herbert Waite

10. Ferritin. Biomineralization of Iron Elizabeth C. Theil, Xiaofeng S. Liu, and Manolis Matzapetakis

11. Magnetism and Molecular Biology of Magnetic Iron Minerals in Bacteria Richard B. Frankel, Sabrina Schübbe, and Dennis A. Bazylinski

12. Biominerals. Recorders of the Past?

Danielle Fortin, Sean R. Langley, and Susan Glasauer

13. Dynamics of Biomineralization and Biodemineralization Lijun Wang and George H. Nancollas

14. Mechanism of Mineralization of Collagen-Based Connective Tissues Adele L. Boskey

15. Mammalian Enamel Formation Janet Moradian-Oldak and Michael L. Paine

16. Mechanical Design of Biomineralized Tissues. Bone and Other Hierarchical Materials Peter Fratzl

17. Bioinspired Growth of Mineralized Tissue Darilis Suárez-González and William L. Murphy

18. Polymer-Controlled Biomimetic Mineralization of Novel Inorganic Materials Helmut Cölfen and Markus Antonietti

Subject Index 


\section{Volume 5: Metallothioneins and Related Chelators}

1. Metallothioneins. Historical Development and Overview Monica Nordberg and Gunnar F. Nordberg

2. Regulation of Metallothionein Gene Expression Kuppusamy Balamurugan and Walter Schaffner

3. Bacterial Metallothioneins Claudia A. Blindauer

4. Metallothioneins in Yeast and Fungi Benedikt Dolderer, Hans-Jürgen Hartmann, and Ulrich Weser

5. Metallothioneins in Plants Eva Freisinger

6. Metallothioneins in Diptera Silvia Atrian

7. Earthworm and Nematode Metallothioneins Stephen R. Stürzenbaum

8. Metallothioneins in Aquatic Organisms: Fish, Crustaceans, Molluscs, and Echinoderms

Laura Vergani

9. Metal Detoxification in Freshwater Animals. Roles of Metallothioneins Peter G. C. Campbell and Landis Hare

10. Structure and Function of Vertebrate Metallothioneins Juan Hidalgo, Roger Chung, Milena Penkowa, and Milan Vašák

11. Metallothionein-3, Zinc, and Copper in the Central Nervous System Milan Vašák and Gabriele Meloni

12. Metallothionein Toxicology: Metal Ion Trafficking and Cellular Protection David H. Petering, Susan Krezoski, and Niloofar M. Tabatabai

13. Metallothionein in Inorganic Carcinogenesis Michael P. Waalkes and Jie Liu

14. Thioredoxins and Glutaredoxins. Functions and Metal Ion Interactions Christopher Horst Lillig and Carsten Berndt

15. Metal Ion-Binding Properties of Phytochelatins and Related Ligands Aurélie Devez, Eric Achterberg, and Martha Gledhill

Subject Index

\section{Volume 6: Metal-Carbon Bonds in Enzymes and Cofactors}

1. Organometallic Chemistry of $\mathrm{B}_{12}$ Coenzymes Bernhard Kräutler

2. Cobalamin- and Corrinoid-Dependent Enzymes Rowena G. Matthews 
3. Nickel-Alkyl Bond Formation in the Active Site of Methyl-Coenzyme M Reductase

Bernhard Jaun and Rudolf K. Thauer

4. Nickel-Carbon Bonds in Acetyl-Coenzyme A Synthases/Carbon Monoxide Dehydrogenases

Paul A. Lindahl

5. Structure and Function of [NiFe]-Hydrogenases

Juan C. Fontecilla-Camps

6. Carbon Monoxide and Cyanide Ligands in the Active Site of [FeFe]-Hydrogenases

John W. Peters

7. Carbon Monoxide as Intrinsic Ligand to Iron in the Active Site of [Fe]-Hydrogenase

Seigo Shima, Rudolf K. Thauer, and Ulrich Ermler

8. The Dual Role of Heme as Cofactor and Substrate in the Biosynthesis of Carbon Monoxide

Mario Rivera and Juan C. Rodriguez

9. Copper-Carbon Bonds in Mechanistic and Structural Probing of Proteins as well as in Situations where Copper Is a Catalytic or Receptor Site Heather R. Lucas and Kenneth D. Karlin

10. Interaction of Cyanide with Enzymes Containing Vanadium and Manganese, Non-Heme Iron, and Zinc

Martha E. Sosa-Torres and Peter M. H. Kroneck

11. The Reaction Mechanism of the Molybdenum Hydroxylase Xanthine Oxidoreductase: Evidence against the Formation of Intermediates Having Metal-Carbon Bonds

Russ Hille

12. Computational Studies of Bioorganometallic Enzymes and Cofactors Matthew D. Liptak, Katherine M. Van Heuvelen, and Thomas C. Brunold

Subject Index

Author Index of MIBS-1 to MIBS-44 and MILS-1 to MILS-6

\section{Volume 7: Organometallics in Environment and Toxicology}

1. Roles of Organometal(loid) Compounds in Environmental Cycles John S. Thayer

2. Analysis of Organometal(loid) Compounds in Environmental and Biological Samples

Christopher F. Harrington, Daniel S. Vidler, and Richard O. Jenkins

3. Evidence for Organometallic Intermediates in Bacterial Methane Formation Involving the Nickel Coenzyme $\mathrm{F}_{430}$ Mishtu Dey, Xianghui Li, Yuzhen Zhou, and Stephen W. Ragsdale 
4. Organotins. Formation, Use, Speciation, and Toxicology Tamas Gajda and Attila Jancsó

5. Alkyllead Compounds and Their Environmental Toxicology Henry G. Abadin and Hana R. Pohl

6. Organoarsenicals: Distribution and Transformation in the Environment Kenneth J. Reimer, Iris Koch, and William R. Cullen

7. Organoarsenicals. Uptake, Metabolism, and Toxicity Elke Dopp, Andrew D. Kligerman, and Roland A. Diaz-Bone

8. Alkyl Derivatives of Antimony in the Environment Montserrat Filella

9. Alkyl Derivatives of Bismuth in Environmental and Biological Media Montserrat Filella

10. Formation, Occurrence and Significance of Organoselenium and Organotellurium Compounds in the Environment

Dirk Wallschläger and Jörg Feldmann

11. Organomercurials. Their Formation and Pathways in the Environment Holger Hintelmann

12. Toxicology of Alkylmercury Compounds Michael Aschner, Natalia Onishchenko, and Sandra Ceccatelli

13. Environmental Bioindication, Biomonitoring, and Bioremediation of Organometal(loid)s

John S. Thayer

14. Methylated Metal(loid) Species in Humans Alfred $V$. Hirner and Albert W. Rettenmeier Subject Index

\section{Volume 8: Metal Ions in Toxicology:} Effects, Interactions, Interdependencies

1. Understanding Combined Effects for Metal Co-Exposure in Ecotoxicology Rolf Altenburger

2. Human Risk Assessment of Heavy Metals: Principles and Applications Jean-Lou C. M. Dorne, George E. N. Kass, Luisa R. Bordajandi, Billy Amzal, Ulla Bertelsen, Anna F. Castoldi, Claudia Heppner, Mari Eskola, Stefan Fabiansson, Pietro Ferrari, Elena Scaravelli, Eugenia Dogliotti, Peter Fuerst, Alan R. Boobis, and Philippe Verger

3. Mixtures and Their Risk Assessment in Toxicology Moiz M. Mumtaz, Hugh Hansen, and Hana R. Pohl

4. Metal Ions Affecting the Pulmonary and Cardiovascular Systems Massimo Corradi and Antonio Mutti

5. Metal Ions Affecting the Gastrointestinal System Including the Liver Declan P. Naughton, Tamás Nepusz, and Andrea Petroczi 
6. Metal Ions Affecting the Kidney Bruce A. Fowler

7. Metal Ions Affecting the Hematological System Nickolette Roney, Henry G. Abadin, Bruce Fowler, and Hana R. Pohl

8. Metal Ions Affecting the Immune System Irina Lehmann, Ulrich Sack, and Jörg Lehmann

9. Metal Ions Affecting the Skin and Eyes Alan B. G. Lansdown

10. Metal Ions Affecting the Neurological System Hana R. Pohl, Nickolette Roney, and Henry G. Abadin

11. Metal Ions Affecting Reproduction and Development Pietro Apostoli and Simona Catalani

12. Are Cadmium and Other Heavy Metal Compounds Acting as Endocrine Disrupters?

Andreas Kortenkamp

13. Genotoxicity of Metal Ions: Chemical Insights Woijciech Bal, Anna Maria Protas, and Kazimierz. S. Kasprzak

14. Metal Ions in Human Cancer Development Erik J. Tokar, Lamia Benbrahim-Tallaa, and Michael P. Waalkes

Subject Index

\section{Volume 9: Structural and Catalytic Roles of Metal Ions in RNA}

1. Metal Ion Binding to RNA Pascal Auffinger, Neena Grover, and Eric Westhof

2. Methods to Detect and Characterize Metal Ion Binding Sites in RNA Michèle C. Erat and Roland K. O. Sigel

3. Importance of Diffuse Metal Ion Binding to RNA Zhi-Jie Tan and Shi-Jie Chen

4. RNA Quadruplexes Kangkan Halder and Jörg S. Hartig

5. The Roles of Metal Ions in Regulation by Riboswitches Adrian Ferré-D'Amaré and Wade C. Winkler

6. Metal Ions: Supporting Actors in the Playbook of Small Ribozymes Alexander E. Johnson-Buck, Sarah E. McDowell, and Nils G. Walter

7. Multiple Roles of Metal Ions in Large Ribozymes Daniela Donghi and Joachim Schnabl

8. The Spliceosome and Its Metal Ions Samuel E. Butcher

9. The Ribosome: A Molecular Machine Powered by RNA Krista Trappl and Norbert Polacek 
10. Metal Ion Requirements in Artificial Ribozymes that Catalyze Aminoacylations and Redox Reactions

Hiroaki Suga, Kazuki Futai, and Koichiro Jin

11. Metal Ion Binding and Function in Natural and Artificial Small RNA Enzymes from a Structural Perspective Joseph E. Wedekind

12. Binding of Kinetically Inert Metal Ions to RNA: The Case of Platinum(II) Erich G. Chapman, Alethia A. Hostetter, Maire F. Osborn, Amanda L. Miller, and Victoria J. DeRose

Subject Index

\section{Volume 10: Interplay between Metal Ions and Nucleic Acids}

1. Characterization of Metal Ion-Nucleic Acid Interactions in Solution Maria Pechlaner and Roland K. O. Sigel

2. Nucleic Acid-Metal Ion Interactions in the Solid State Katsuyuki Aoki and Kazutaka Murayama

3. Metal Ion-Promoted Conformational Changes of Oligonucleotides Bernhard Spingler

4. G-Quadruplexes and Metal Ions Nancy H. Campbell and Stephen Neidle

5. Metal Ion-Mediated DNA-Protein Interactions Barbara Zambelli, Francesco Musiani, and Stefano Ciurli

6. Spectroscopic Investigations of Lanthanide Ion Binding to Nucleic Acids Janet R. Morrow and Christopher M. Andolina

7. Oxidative DNA Damage Mediated by Transition Metal Ions and Their Complexes Geneviève Pratviel

8. Metal Ion-Dependent DNAzymes and Their Applications as Biosensors Tian Lan and Yi Lu

9. Enantioselective Catalysis at the DNA Scaffold Almudena García-Fernández and Gerard Roelfes

10. Alternative DNA Base Pairing through Metal Coordination Guido H. Clever and Mitsuhiko Shionoya

11. Metal-Mediated Base Pairs in Nucleic Acids with Purine- and PyrimidineDerived Nucleosides

Dominik A. Megger, Nicole Megger, and Jens Müller

12. Metal Complex Derivatives of Peptide Nucleic Acids (PNA)

Roland Krämer and Andrij Mokhir

Subject Index 


\section{Volume 11: Cadmium: From Toxicity to Essentiality}

1. The Bioinorganic Chemistry of Cadmium in the Context of Its Toxicity Wolfgang Maret and Jean-Marc Moulis

2. Biogeochemistry of Cadmium and Its Release to the Environment Jay T. Cullen and Maria T. Maldonado

3. Speciation of Cadmium in the Environment Francesco Crea, Claudia Foti, Demetrio Milea, and Silvio Sammartano

4. Determination of Cadmium in Biological Samples Katrin Klotz, Wobbeke Weistenhöfer, and Hans Drexler

5. Imaging and Sensing of Cadmium in Cells Masayasu Taki

6. Use of ${ }^{113} \mathrm{Cd}$ NMR to Probe the Native Metal Binding Sites in Metalloproteins: An Overview Ian M. Armitage, Torbjörn Drakenberg, and Brian Reilly

7. Solid State Structures of Cadmium Complexes with Relevance for Biological Systems

Rosa Carballo, Alfonso Castiñeiras, Alicia Domínguez-Martín, Isabel García Santos, and Juan Niclós-Gutierrez

8. Complex Formation of Cadmium(II) with Sugar Residues, Nucleobases, Phosphates, Nucleotides, and Nucleic Acids Roland K. O. Sigel, Miriam Skilandat, Astrid Sigel, Bert P. Operschall, and Helmut Sigel

9. Cadmium(II) Complexes of Amino Acids and Peptides Imre Sóvágó and Katalin Várnagy

10. Natural and Artificial Proteins Containing Cadmium Anna F. Peacock and Vincent L. Pecoraro

11. Cadmium in Metallothioneins Eva Freisinger and Milan Vašák

12. Cadmium-Accumulating Plants Hendrik Küpper and Barbara Leitenmaier

13. Cadmium Toxicity in Plants Elisa Andresen and Hendrik Küpper

14. Toxicology of Cadmium and Its Damage to Mammalian Organs Frank Thévenod and Wing-Kee Lee

15. Cadmium and Cancer Andrea Hartwig

16. Cadmium in Marine Phytoplankton Yan Xu and François M. M. Morel

Subject Index 


\section{Volume 12: Metallomics and the Cell}

Guest Editor: Lucia Banci

1. Metallomics and the Cell: Some Definitions and General Comments Lucia Banci and Ivano Bertini

2. Technologies for Detecting Metals in Single Cells James E. Penner-Hahn

3. Sodium/Potassium Homeostasis in the Cell Michael J. V. Clausen and Hanna Poulsen

4. Magnesium Homeostasis in Mammalian Cells Andrea M. P. Romani

5. Intracellular Calcium Homeostasis and Signaling Marisa Brini, Tito Cali, Denis Ottolini, and Ernesto Carafoli

6. Manganese Homeostasis and Transport Jerome Roth, Silvia Ponzoni, and Michael Aschner

7. Control of Iron Metabolism in Bacteria Simon Andrews, Ian Norton, Arvindkumar S. Salunkhe, Helen Goodluck, Wafaa S. M. Aly, Hanna Mourad-Agha, and Pierre Cornelis

8. The Iron Metallome in Eukaryotic Organisms Adrienne C. Dlouhy and Caryn E. Outten

9. Heme Uptake and Metabolism in Bacteria David R. Benson and Mario Rivera

10. Cobalt and Corrinoid Transport and Biochemistry Valentin Cracan and Ruma Banerjee

11. Nickel Metallomics: General Themes Guiding Nickel Homeostasis Andrew M. Sydor and Deborah B. Zamble

12. The Copper Metallome in Prokaryotic Cells Christopher Rensing and Sylvia Franke McDevitt

13. The Copper Metallome in Eukaryotic Cells Katherine E. Vest, Hayaa F. Hashemi, and Paul A. Cobine

14. Zinc and the Zinc Proteome Wolfgang Maret

15. Metabolism of Molybdenum Ralf R. Mendel

16. Comparative Genomics Analysis of the Metallomes Vadim N. Gladyshev and Yan Zhang

Subject Index

\section{Volume 13: Interrelations between Essential Metal Ions and Human Diseases}

1. Metal Ions and Infectious Diseases. An Overview from the Clinic Peggy L. Carver 
2. Sodium and Potassium in Health and Disease

Hana R. Pohl, John S. Wheeler, and H. Edward Murray

3. Magnesium in Health and Disease Andrea M. P. Romani

4. Calcium in Health and Disease Marisa Brini, Denis Ottolini, Tito Calì, and Ernesto Carafoli

5. Vanadium. Its Role for Humans Dieter Rehder

6. Chromium. Is It Essential, Pharmacologically Relevant, or Toxic? John B. Vincent

7. Manganese in Health and Disease Daiana Silva Avila, Robson Luiz Puntel, and Michael Aschner

8. Iron: Effect of Overload and Deficiency Robert C. Hider and Xiaole Kong

9. Cobalt: Its Role in Health and Disease Kazuhiro Yamada

10. Nickel and Human Health Barbara Zambelli and Stefano Ciurli

11. Copper: Effects of Deficiency and Overload Ivo Scheiber, Ralf Dringen, and Julian F. B. Mercer

12. Zinc and Human Disease Wolfgang Maret

13. Molybdenum in Human Health and Disease Guenter Schwarz and Abdel A. Belaidi

14. Silicon: The Health Benefits of a Metalloid Keith R. Martin

15. Arsenic. Can this Toxic Metalloid Sustain Life? Dean E. Wilcox

16. Selenium. Role of the Essential Metalloid in Health Suguru Kurokawa and Marla J. Berry

Subject Index

\section{Volume 14: The Metal-Driven Biogeochemistry of Gaseous Compounds in the Environment}

Guest Editors: Peter M. H. Kroneck and Martha E. Sosa Torres

1. The Early Earth Atmosphere and Early Life Catalysts Sandra I. Ramírez Jiménez

2. Living on Acetylene. A Primordial Energy Source Felix ten Brink 
3. Carbon Monoxide. Toxic Gas and Fuel for Anaerobes and Aerobes: Carbon Monoxide Dehydrogenases Jae-Hun Jeoung, Jochen Fesseler, Sebastian Goetzl, and Holger Dobbek

4. Investigations of the Efficient Electrocatalytic Interconversions of Carbon Dioxide and Carbon Monoxide by Nickel-Containing Carbon Monoxide Dehydrogenases Vincent C.-C. Wang, Stephen W. Ragsdale, and Fraser A. Armstrong

5. Understanding and Harnessing Hydrogenases

Biological Dihydrogen Catalysts Alison Parkin

6. Biochemistry of Methyl-Coenzyme M Reductase: The Nickel Metalloenzyme that Catalyzes the Final Step in Synthesis and the First Step in Anaerobic Oxidation of the Greenhouse Gas Methane Stephen W. Ragsdale

7. Cleaving the N,N Triple Bond: The Transformation of Dinitrogen to Ammonia by Nitrogenases Chi Chung Lee, Markus W. Ribbe, and Yilin Hu

8. No Laughing Matter: The Unmaking of the Greenhouse Gas Dinitrogen Monoxide by Nitrous Oxide Reductase Lisa K. Schneider, Anja Wüst, Anja Pomowski, Lin Zhang, and Oliver Einsle

9. The Production of Ammonia by Multiheme Cytochromes $c$ Jörg Simon and Peter M. H. Kroneck

10. Hydrogen Sulfide: A Toxic Gas Produced by Dissimilatory Sulfate and Sulfur Reduction and Consumed by Microbial Oxidation Larry L. Barton, Marie-Laure Fardeau, and Guy D. Fauque

11. Transformations of Dimethylsulfide Ulrike Kappler and Hendrik Schäfer

Subject Index

\section{Volume 15: Sustaining Life on Planet Earth:} Metalloenzymes Mastering Dioxygen and Other Chewy Gases Guest Editors: Peter M. H. Kroneck and Martha E. Sosa Torres

1. The Magic of Dioxygen Martha E. Sosa Torres, Juan P. Saucedo-Vázquez, and Peter M. H. Kroneck

2. Light-Dependent Production of Dioxygen in Photosynthesis Junko Yano, Jan Kern, Vittal K. Yachandra, Håkan Nilsson, Sergey Koroidov, and Johannes Messinger

3. Production of Dioxygen in the Dark: Dismutases of Oxyanions Jennifer L. DuBois and Sunil Ojha 
4. Respiratory Conservation of Energy with Dioxygen:

Cytochrome $c$ Oxidase

Shinya Yoshikawa, Atsuhiro Shimada, and Kyoko Shinzawa-Itoh

5. Transition Metal Complexes and the Activation of Dioxygen

Gereon M. Yee and William B. Tolman

6. Methane Monooxygenase: Functionalizing Methane at Iron and Copper Matthew H. Sazinsky and Stephen J. Lippard

7. Metal Enzymes in "Impossible" Microorganisms Catalyzing the Anaerobic Oxidation of Ammonium and Methane Joachim Reimann, Mike S. M. Jetten, and Jan T. Keltjens

Subject Index

\section{Volume 16: The Alkali Metal Ions: Their Roles for Life}

1. Bioinorganic Chemistry of the Alkali Metal Ions Youngsam Kim, Thuy Tien Nguyen, and David G. Churchill

2. Determination of Alkali Ions in Biological and Environmental Samples Peter C. Hauser

3. Solid State Structures of Alkali Metal Ion Complexes Formed by Low-Molecular-Weight Ligands of Biological Relevance Katsuyuki Aoki, Kazutaka Murayama, and Ning-Hai Hu

4. Discriminating Properties of Alkali Metal Ions towards the Constituents of Proteins and Nucleic Acids. Conclusions from Gas-Phase and Theoretical Studies Mary T. Rodgers and Peter B. Armentrout

5. Alkali-Metal Ion Complexes with Phosphates, Nucleotides, Amino Acids, and Related Ligands of Biological Relevance. Their Properties in Solution Francesco Crea, Concetta De Stefano, Claudia Foti, Gabriele Lando, Demetrio Milea, and Silvio Sammartano

6. Sodium and Potassium Interactions with Nucleic Acids Pascal Auffinger, Luigi D'Ascenzo, and Eric Ennifar

7. Role of Alkali Metal Ions in G-Quadruplex Nucleic Acid Structure and Stability

Eric Largy, Jean-Louis Mergny, and Valérie Gabelica

8. Sodium and Potassium Ions in Proteins and in Enzyme Catalysis Milan Vašak and Joachim Schnabl

9. Roles and Transport of Sodium and Potassium in Plants Manuel Nieves-Cordones, Fouad Razzaq Al Shiblawi, and Hervé Sentenac

10. Potassium versus Sodium Selectivity in Monovalent Ion Channel Selectivity Filters Carmay Lim and Todor Dudev 
11. Sodium as Coupling Cation in Respiratory Energy Conversion Günter Fritz and Julia Steuber

12. Sodium-Proton $\left(\mathrm{Na}^{+} / \mathrm{H}^{+}\right)$Antiporters: Properties and Roles in Health and Disease Etana Padan and Meytal Landau

13. Proton-Potassium $\left(\mathrm{H}^{+} / \mathrm{K}^{+}\right)$ATPases: Properties and Roles in Health and Disease Hideki Sakai, Takuto Fujii, and Noriaki Takeguchi

14. Bioinspired Artificial Sodium and Potassium Channels Nuria Vázquez-Rodríguez, Alberto Fuertes, Manuel Amorín, and Juan R. Granja

15. Lithium in Medicine: Mechanisms of Action Duarte Mota de Freitas, Brian D. Leverson, and Jesse L. Goossens

16. Sodium and Potassium Relating to Parkinson's Disease and Traumatic Brain Injury

Yonghwang Ha, Jeong A. Jeong, Youngsam Kim, and David G. Churchill Subject Index

\section{Volume 17: Lead: Its Effects on Environment and Health}

1. The Bioinorganic Chemistry of Lead in the Context of Its Toxicity Wolfgang Maret

2. Biogeochemistry of Lead. Its Release to the Environment and Chemical Speciation Jay T. Cullen and Jason McAlister

3. Analytical Methods for the Determination of Lead in the Environment Peter C. Hauser

4. Smart Capsules for Lead Removal from Industrial Wastewater Bartosz Tylkowski and Renata Jastrząb

5. Lead Speciation in Microorganisms Theodora J. Stewart

6. Human Biomonitoring of Lead Exposure Katrin Klotz and Thomas Göen

7. Solid State Structures of Lead Complexes with Relevance for Biological Systems

Katsuyuki Aoki, Kazutaka Murayama, and Ning-Hai Hu

8. Lead(II) Complexes of Amino Acids, Peptides, and Other Related Ligands of Biological Interest Etelka Farkas and Péter Buglyó

9. Lead(II) Binding in Metallothioneins Daisy L. Wong, Maureen E. Merrifield-MacRae, and Martin J. Stillman 
10. Lead(II) Binding in Natural and Artificial Proteins

Virginia Cangelosi, Leela Ruckthong, and Vincent L. Pecoraro

11. Complex Formation of Lead(II) with Nucleotides and Their Constituents Astrid Sigel, Bert P. Operschall, and Helmut Sigel

12. The Role of Lead(II) in Nucleic Acids Joana Palou-Mir, Miquel Barceló-Oliver, and Roland K. O. Sigel

13. Historical View on Lead: Guidelines and Regulations Hana R. Pohl, Susan Z. Ingber, and Henry G. Abadin

14. Environmental Impact of Alkyl Lead(IV) Derivatives Montserrat Filella and Josep Bone

15. Lead Toxicity in Plants Hendrik Küpper

16. Toxicology of Lead and Its Damage to Mammalian Organs

Samuel Caito, Ana Carolina B. Almeida Lopes, Monica M. B. Paoliello, and Michael Aschner

Subject Index

\section{Volume 18: Metallo-Drugs: Development and Action} of Anticancer and Antitumor Agents

1. Cisplatin and Oxaliplatin: Our Current Understanding of Their Actions Imogen A. Riddell and Stephen J. Lippard

2. Polynuclear Platinum Complexes. Structural Diversity and DNA-Binding Viktor Brabec, Jana Kasparkova, Vijay Menon, and Nicholas P. Farrell

3. Platinum(IV) Prodrugs

V. Venkatesh and Peter J. Sadler

4. Metalloglycomics

Nicholas P. Farrell, Anil K. Gorle, Erica J. Peterson, and

Susan J. Berners-Price

5. The Deceptively Similar Ruthenium(III) Drug Candidates KP1019 and NAMI-A Have Different Actions. What Did We Learn in the Past 30 Years? Enzo Alessio and Luigi Messori

6. Multinuclear Organometallic Ruthenium-Arene Complexes for Cancer Therapy

Maria V. Babak and Wee Han Ang

7. Medicinal Chemistry of Gold Anticancer Metallodrugs Angela Casini, Raymond Wai-Yin Sun, and Ingo Ott

8. Coordination Complexes of Titanium(IV) for Cancer Therapy Edit Y. Tshuva and Maya Miller

9. Health Benefits of Vanadium and Its Potential as an Anticancer Agent Debbie C. Crans, Lining Yang, Allison Haase, and Xiaogai Yang

10. Gallium Complexes as Anticancer Drugs

Christopher R. Chitambar 
11. Non-covalent Metallo-Drugs: Using Shape to Target DNA and RNA Junctions and Other Nucleic Acid Structures

Lucia Cardo and Michael J. Hannon

12. Nucleic Acid Quadruplexes and Metallo-Drugs

Ramon Vilar

13. Antitumor Metallo-Drugs that Target Proteins

Matthew P. Sullivan, Hannah U. Holtkamp, and Christian G. Hartinger

14. Metallointercalators and Metalloinsertors: Structural Requirements for DNA Recognition and Anticancer Activity

Ulrich Schatzschneider

15. Iron and Its Role in Cancer Defence: A Double-Edged Sword Frank Thévenod

16. Copper Complexes in Cancer Therapy Delphine Denoyer, Sharnel A. S. Clatworthy, and Michael Cater

17. Targetting Zinc Signalling to Prevent Cancer

Silvia Ziliotto, Olivia Ogle, and Kathryn M. Taylor

Subject Index

\section{Volume 19: Essential Metals in Medicine: Therapeutic Use and Toxicity of Metal Ions in the Clinic Guest Editor: Peggy L. Carver}

1. Metals in Medicine: The Therapeutic Use of Metal Ions in the Clinic Peggy L. Carver

2. Small Molecules: The Past or the Future in Drug Innovation? Anne Robert, Françoise Benoit-Vical, Yan Liu, and Bernard Meunier

3. Iron Chelation for Iron Overload in Thalassemia

Guido Crisponi, Valeria M. Nurchi, and Joanna I. Lachowicz

4. Ironing out the Brain Roberta J. Ward and Robert R. Crichton

5. Infections Associated with Iron Administration Manfred Nairz and Guenter Weiss

6. Iron Oxide Nanoparticle Formulations for Supplementation Amy B. Pai

7. Building a Trojan Horse: Siderophore-Drug Conjugates for the Treatment of Infectious Diseases Elzbieta Gumienna-Kontecka and Peggy L. Carver

8. Developing Vanadium as an Antidiabetic or Anticancer Drug: A Clinical and Historical Perspective

Debbie C. Crans, LaRee Henry, Gabriel Cardiff, and Barry I. Posner

9. Chromium Supplementation in Human Health, Metabolic Syndrome, and Diabetes

Wolfgang Maret 
10. Manganese: Its Role in Disease and Health Keith M. Erikson and Michael Aschner

11. Cobalt-Schiff Base Complexes: Preclinical Research and Potential Therapeutic Uses Elizabeth A. Bajema, Kaleigh F. Roberts, and Thomas J. Meade

12. Copper Depletion as a Therapeutic Strategy in Cancer Jay Lopez, Divya Ramchandani, and Linda T. Vahdat

13. Metal Compounds in the Development of Antiparasitic Agents: Rational Design from Basic Chemistry to the Clinic Dinorah Gambino and Lucía Otero

14. Chemical and Clinical Aspects of Metal-Containing Antidotes for Poisoning by Cyanide

Sigrídur G. Suman and Johanna M. Gretarsdottir

Subject Index

\section{Volume 20: Transition Metals and Sulfur: A Strong Relationship for Life} Guest Editors: Martha E. Sosa Torres and Peter M. H. Kroneck

1. Introduction. Transition Metals and Sulfur Martha E. Sosa Torres and Peter M. H. Kroneck

2. Sulfur, the Versatile Non-metal Martha E. Sosa-Torres, Alfonso Rito Morales, Alejandro Solano Peralta, and Peter M. H. Kroneck

3. The Type 1 Blue Copper Site: From Electron Transfer to Biological Function

Trinidad Arcos-López, Nils Schuth, and Liliana V. Quintanar

4. Purple Mixed-Valent Copper A Marcos N. Morgada, Daniel H. Murgida, and Alejandro J. Vila

5. The Tetranuclear Copper-Sulfide Center of Nitrous Oxide Reductase Sofia R. Pauleta, Marta S. P. Carepo, and Isabel Moura

6. Cytochrome $\mathrm{P}_{450}$, the Dioxygen-Activating Heme Thiolate F. Miguel Castro Martínez, R. Daniel Páez López, Pedro D. Sarmiento Pavía, Martha E. Sosa-Torres, and Peter M. H. Kroneck

7. Basic Iron-Sulfur Redox Centers Claudia Andreini and Simone Ciofi-Baffoni

8. The Cofactors of Nitrogenases Ivana Djurdjevic, Christian Trncik, Michael Rohde, Jakob Gies, Katharina Grunau, Florian Schneider, Susana L. A. Andrade, and Oliver Einsle

9. Molybdenum and Tungsten Cofactors and the Reactions They Catalyze Khadanand KC and Martin L. Kirk

10. The Siroheme-[4Fe-4S] Coupled Center Isabel Askenazy and M. Elizabeth Stroupe 
11. Nickel, Iron, Sulfur Sites

Yulia Ilina, Berta M. Martins, Jae-Hun Jeoung, and Holger Dobbek

12. Zinc Fingers

Gaetano Malgieri, Luigi Russo, Gianluca D’Abrosco, Ilaria Baglivo, Paolo V. Pedone, Roberto Fattorusso, and Carla Isernia

Subject Index

Volume 21: Metals, Microbes, and Minerals: The Biogeochemical Side of Life Guest Editors: Peter M. H. Kroneck and Martha E. Sosa-Torres (this book)

Volume 22: Metal Ions in Bio-Imaging Techniques

(tentative)

1. Metal Ions in Bio-Imaging Techniques: A Short Overview Sergey Shuvaev and Peter Caravan

2. Gadolinium(III)-Based Contrast Agents for Magnetic Resonance Imaging. A Re-Appraisal

Gyula Tircsó, Enikö Molnár, Tibor Csupász, Zoltán Garda, Richárd Botár, Ferenc K. Kálmán, Zoltán Kovácz, and Imre Tóth

3. Manganese Complexes as Contrast Agents for Magnetic Resonance Imaging

Sara Lacerda, Daouda Ndiaye, and Éva Tóth

4. Metal Ion Complexes in Paramagnetic Chemical Exchange Saturation Transfer (ParaCEST) Aurora Rodríguez-Rodríguez, Moritz Zaiss, David Esteban-Gómez, Goran Angelovski, and Carlos Platas-Iglesia

5. Lanthanide Complexes Used for Optical Imaging Thomas J. Sфrensen and Stephen Faulkner

6. Radiometals for Positron Emission Tomography (PET) Imaging Shion-Hye Ahn, Alexia G. Cosby, Angus J. Koller, Kirsten E. Martin, Apurva Pandey, Brett A. Vaughn, and Eszter Boros

7. ${ }^{99 \mathrm{~m}}$ Technetium-Based Imaging Agents and Developments in ${ }^{99} \mathrm{Tc}$ Chemistry Roger Alberto and Quaisar Nadeem

8. Paramagnetic Metal Ion Probes for ${ }^{19} \mathrm{~F}$ Magnetic Resonance Imaging Petr Hermann, Jan Blahut, Jan Kotek, and Vit Herynek

9. Iron Oxide Nanoparticles for Bio-Imaging Carlos F. G. C. Geraldes and Marie-Hélène Delville

10. Magnetic Resonance Contrast Enhancement and Therapeutic Properties of Corrole Nanoparticles

James Teh and Lali K. Medina-Kauwe

11. Theranostics as Driven by Positron Emission Tomography

Suresh Pandey, Giovanni G. Giovenzana, Dezsö Szikra, and Zsolt Baranyai 
12. Magnetic Resonance Theranostics: An Overview of Gd(III)-Based Strategies and Magnetic Particle Imaging Shaunna M. McLeod and Thomas J. Meade

13. Luminescence Imaging of Cancer Cells Jorge Monteiro, Josiane A. Sobrinho, and Ana de Bettencourt-Dias

14. Iridium(III) Complexes in Bio-Imaging Including Mitochondria Cai-Ping Tan, Jie Wang, Liang-Nian Ji, and Zong-Wan Mao

15. Imaging Bacteria with Contrast-Enhanced Magnetic Resonance Casey J. Adams and Thomas J. Meade

16. Transition Metals ans Imaging Probes in Neurobiology and Neurodegenerative Diseases

Ho Yu Au-Yeung and Ka Yan Tong

17. Heavy Elements for X-Ray Contrast Yuxi C. Dong and David P. Cormode

Subject Index

Comments and suggestions with regard to contents, topics, and the like for future volumes of the series are welcome. 
